\title{
A Study on Making Rigid Polyurethane Foams from Vietnam Rubber Seed Oil-Based Polyol by Using Water as a Single Blowing Agent
}

\author{
Nguyen Thi Thuy ${ }^{1}$ and Pham Ngoc $\operatorname{Lan}^{2}$ \\ ${ }^{1}$ Hanoi University of Science and Technology, Hanoi 10000, Vietnam \\ ${ }^{2}$ VNU-University of Science, Hanoi 10000, Vietnam \\ Correspondence should be addressed to Nguyen Thi Thuy; thuy.nguyenthi1@hust.edu.vn
}

Received 1 December 2020; Revised 26 December 2020; Accepted 5 January 2021; Published 18 January 2021

Academic Editor: Mehdi Salami-Kalajahi

Copyright (C) 2021 Nguyen Thi Thuy and Pham Ngoc Lan. This is an open access article distributed under the Creative Commons Attribution License, which permits unrestricted use, distribution, and reproduction in any medium, provided the original work is properly cited.

\begin{abstract}
In this work, for making rigid polyurethane foams, only water was used to serve as a blowing agent. Vietnam rubber seed oil-based polyol was also used. Following our previous research results, water content was fixed at $4 \mathrm{wt} . \%$ and glycerol content at 3 wt.\%, as compared to biopolyol. The effect of the $\mathrm{NCO} / \mathrm{OH}$ ratio, main catalyst (dibutyltin dilaurate), cocatalyst (triethylamine), and surfactant content as well as the surfactants on performances of foams was investigated through compressive strength, density, cell size, and size distribution. A suitable formulation for making foam by using biopolyol made from rubber seed oil was established. In parallel with it, foam based on commercial polyol derived from petroleum was also manufactured. The characteristics of the foaming process were assessed. The mechanical properties, thermal behavior, water absorption, and dimensional stability of foams were evaluated. The cellular morphology study shows that the cells of foam based on biopolyol were closed and rather uniform; however, cell size was $3 \%$ bigger and cell walls were also a bit thicker. The results showed that the properties of foam based on biopolyol were similar to those of petrofoams. This result may open a possibility to replace petropolyol with renewable biopolyol in foam fabrication.
\end{abstract}

\section{Introduction}

Many research topics involving polyurethane foams have been ongoing since they were discovered in 1940 [1]. Thanks to the outstanding properties such as high strength, no difficulty forming complex shapes, foams made from polyurethane are commonly used in many different fields, for example, shipbuilding, insulation materials, construction, and production of footwear and mattresses [1-4]. Besides diisocyanates, another major ingredient for polyurethane production is a polyol. Usually, a type of polyether or polyester is used as a polyol for this purpose.

Most of the commercial polyols are derived from petrochemical resources $[1,5]$. It is known that this resource is limited and increasingly depleted very fast. In addition, their unfriendly influence on the environment is very concerning $[1,6]$. Moreover, the foam based on polypropylene oxide is sensitive to hydrolysis and tends to absorb water [2]. This motivated fabrication of a new material, polyurethane foams, in which part or all of the petrodiol was replaced by a new, renewable diol of biological origin [1, 5, 7-11]. Vegetable oils are of increasing interest as a starting renewable material for environmentally friendly biopolymer fabrication [12-14]. Vegetable oils with lots of double bonds on the fatty acid backbone chains are converted into biopolyols, which are used as one of the main ingredients in the synthesis of polyurethanes. The hydroxymethylated castor oil and polyol esters of castor acids have been used to prepare rigid polyurethane foams since 1974 [15]. In addition, many other oils have been used to be converted to biopolyols for polyurethane synthesis. They are soybean oil $[2,4-8,10,14-16]$, rapeseed oil $[3,17,18]$, linseed oil $[10,19,20]$, palm oil [21, $22]$, safflower oil $[7,15]$, sunflower oil $[7,10]$, and others $[7,10,20]$. In fact, most plant oils are commonly used as 
TABLE 1: Formulation of rigid polyurethane foam based on rubber seed oil.

\begin{tabular}{|c|c|c|c|c|c|c|c|}
\hline No. & Foams & Water & Glycerol & $\mathrm{NCO} / \mathrm{OH}$ & Dibutyltin dilaurate & Silicone & Amine \\
\hline 1.1 & Sn 0 & \multirow{4}{*}{4} & \multirow{4}{*}{3} & \multirow{4}{*}{0.8} & 0 & \multirow{4}{*}{0} & \multirow{4}{*}{0} \\
\hline 1.2 & Sn3 & & & & 0.3 & & \\
\hline 1.3 & Sn 4 & & & & 0.4 & & \\
\hline 1.4 & Sn5 & & & & 0.5 & & \\
\hline 2.1 & OSOA & \multirow{3}{*}{4} & \multirow{3}{*}{3} & \multirow{3}{*}{0.8} & \multirow{3}{*}{0.4} & 0 & 0 \\
\hline 2.2 & $25 \mathrm{~S} 2 \mathrm{~A}$ & & & & & 0.25 (L580) & \multirow{2}{*}{0.2} \\
\hline 2.3 & $35 \mathrm{~S} 2 \mathrm{~A}$ & & & & & 0.35 (L580) & \\
\hline 2.4 & L627 & \multirow{4}{*}{4} & \multirow{4}{*}{3} & \multirow{4}{*}{0.8} & \multirow{4}{*}{0.4} & L627 & \multirow{4}{*}{0.2} \\
\hline 2.5 & L580 & & & & & L580 & \\
\hline 2.6 & B8158 & & & & & B8158 & \\
\hline 2.7 & B8298 & & & & & B8298 & \\
\hline 3.1 & $\mathrm{R} 8.35$ & \multirow{5}{*}{4} & \multirow{5}{*}{3} & 0.8 & \multirow{5}{*}{0.4} & \multirow{5}{*}{0.35 (L580) } & \multirow{5}{*}{0.2} \\
\hline 3.2 & R9.35 & & & 0.9 & & & \\
\hline 3.3 & $\mathrm{R} 10.35$ & & & 1.0 & & & \\
\hline 3.4 & $\mathrm{R} 11.35$ & & & 1.1 & & & \\
\hline 3.5 & $\mathrm{R} 12.35$ & & & 1.2 & & & \\
\hline 3.6 & $\mathrm{R} 8.25$ & \multirow{5}{*}{4} & \multirow{5}{*}{3} & 0.8 & \multirow{5}{*}{0.4} & \multirow{5}{*}{0.25 (L580) } & \multirow{5}{*}{0.2} \\
\hline 3.7 & R9.25 & & & 0.9 & & & \\
\hline 3.8 & $\mathrm{R} 10.25$ & & & 1.0 & & & \\
\hline 3.9 & $\mathrm{R} 11.25$ & & & 1.1 & & & \\
\hline 3.10 & $\mathrm{R} 12.25$ & & & 1.2 & & & \\
\hline 4.1 & A1.35 & \multirow{8}{*}{4} & \multirow{8}{*}{3} & \multirow{8}{*}{1.1} & \multirow{8}{*}{0.4} & \multirow{5}{*}{0.35 (L580) } & 0.1 \\
\hline 4.2 & A2.35 & & & & & & 0.2 \\
\hline 4.3 & A 3.35 & & & & & & 0.3 \\
\hline 4.4 & A4.35 & & & & & & 0.4 \\
\hline 4.5 & A1.25 & & & & & & 0.1 \\
\hline 4.6 & A 2.25 & & & & & & 0.2 \\
\hline 4.7 & A 3.25 & & & & & 0.25 (L580) & 0.3 \\
\hline 4.8 & A4.25 & & & & & & 0.4 \\
\hline
\end{tabular}

food, so oils such as castor oil [7, 9, 23, 24], rubber seed oil [1, 25], hemp oil [18], or waste cooking oil [26], being inedible, have received a lot of attention from scientists in terms of feedstock to make suitable materials. Although rubber seed oil does not face food security problems and has potential for various uses, until now, the amount of studies on polyurethanes based on this oil is relatively modest. In 2008, Bakare et al. showed success in the use of rubber seed oil monoglyceride, which was prepared by the alcoholysis method, as a biopolyol to prepare polyurethane [25]. By 2016, Saetung et al. extracted, refined, and transformed rubber seed oil into biopolyol. It showed that upon modification of rubber seed oil taking place, epoxidation and ring-opening reaction occurred at the same time [1]. The influence of hydroxyl value (120 and $230 \mathrm{mg} \mathrm{KOH} / \mathrm{g}$ ) of the obtained biopolyols and the NCO index as well as water content on the properties and characteristics of the foams were studied [1]. This paper presents a study on making rigid polyurethane foams from Vietnam rubber seed oil-based polyol by using water as a single blowing agent. It has used glycerol together with rubber seed oil polyol with a hydroxyl value of $450 \mathrm{mg} \mathrm{KOH} / \mathrm{g}$ for the formulation of rigid polyurethane. In addition, this study presents an investigation on the influence of the main and cocatalyst content, type and amount of surfactants, and $\mathrm{NCO} / \mathrm{OH}$ ratio on the performance of polyurethane foams, through which the formulation of polyurethane foams based on rubber seed oil-derived polyol was established. The performance of the synthesized rigid foams was also evaluated and compared with that of rigid foams obtained from the commercial petropolyol.

\section{Materials and Methods}

2.1. Materials. The biopolyol based on rubber seed oil was fabricated in a laboratory of Hanoi University of Science and Technology, Vietnam. The reaction of converting double bonds in the oil into hydroxyl groups in biopolyol was done by using a catalyst system based on tungsten salt such as sodium tungstate dihydrate at $100^{\circ} \mathrm{C}$ for 2 hours. Following other papers [27, 28], this catalyst system would form a peroxophosphotungstate catalytic complex to oxidize the double bonds in the oil. The hydroxyl value of the biopolyol 
was $450 \mathrm{mg} \mathrm{KOH} / \mathrm{g}$. Dibutyl dilaurate and glycerine (assay $\geq 98.9 \%$ ) were supplied by Sigma-Aldrich. Triethylamine was obtained from Air Products, Singapore. Isocyanate Suprasec 5005 (MDI, average functionality: 2.7; isocyanate value: 30.0-31.5 wt.\%) and Polyol Daltoform MH 25646 were supplied by Polyurethanes Huntsman, USA. Silicone B8158 and B8298 were sold by Evonik, Germany. Nix silicone L580 and L627 were supplied by Momentive, USA.

\subsection{Methods}

2.2.1. Preparation of Foam. In this study, water alone served as a blowing agent in the fabrication of rigid foams. Also, the crosslinker glycerol, main catalyst dibutyltin dilaurate, cocatalyst triethylamine, and surfactant silicone were used. The number of ingredients in this study was calculated as a percentage of polyol mass. Based on our previous research results, for this study, the water content of $4 \mathrm{wt} . \%$ was selected, the content of glycerol was $3 \mathrm{wt} . \%$, as compared to biopolyol [29]. Foam names and the content of ingredients in the recipe are shown in Table 1 . As shown in Table 1, some foams such as $0 \mathrm{~S} 0 \mathrm{~A}$ and $\mathrm{Sn} 4$ or $35 \mathrm{~S} 2 \mathrm{~A}, \mathrm{~L} 580, \mathrm{R} 8.35$, and $\mathrm{A} 2.35$ or $25 \mathrm{~S} 2 \mathrm{~A}, \mathrm{R} 8.25$, and $\mathrm{A} 2.25$ had the same content and compositions.

All the components were mixed in a plastic cup before adding isocyanate. The obtained mixture was stirred for 5 seconds before pouring into the mold. The samples were then kept under room condition $\left(25^{\circ} \mathrm{C}\right.$ and $\left.50 \% \mathrm{RH}\right)$ for a week before testing.

2.2.2. Evaluation of Rigid Foam Properties. Dimensional stability and water absorption of rigid foams were determined according to ISO 2796 and ISO 2896 standards, respectively. Core density was determined following ISO 845 standard, and compressive strength (10\%) of rigid foams was obtained following ISO 844 standard on Instron equipment, USA. The thermal properties were analyzed on (DTA/DSC/TGA) Labsys Evo S60/58988 (France). The morphologies of samples were analyzed using a scanning electron microscope (SEM, JSM-6360/6360LV Japan). The pore radius of cells was measured by using a Dino-Lite USB digital microscope (China).

\section{Results and Discussion}

3.1. Effect of the Main Catalyst Dibutyltin Dilaurate. The content of the main catalyst changed from 0 to $0.5 \mathrm{wt} . \%$ as compared to biopolyol, and the properties of Sn3, Sn4, and Sn5 foams such as the core density, compressive strength, and average pore radius are presented in Figure 1.

The water, glycerol, and $\mathrm{NCO} / \mathrm{OH}$ molar ratio were fixed, and the reaction of $\mathrm{NCO}$ and $\mathrm{OH}$ depended strongly on the main catalyst. Figure 1 shows that the compressive strength increased from 125.11 to $143.95 \mathrm{kPa}$ (by $15.1 \%$ ) if the dibutyltin dilaurate content increased from 0 to $0.4 \mathrm{wt} . \%$. It then reduced by $10.5 \%$ when the dibutyltin dilaurate loading continued increasing. The presence of the main catalyst directly affected the formation of urethane groups and indirectly affected the compressive strength of foams. The higher the main catalyst content, the more urethane groups are formed,

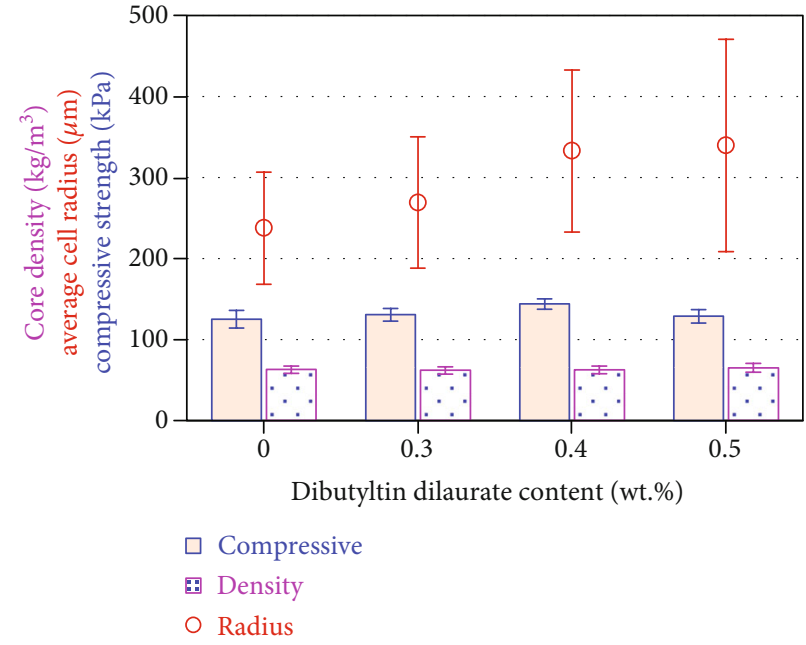

FIGURE 1: Dependence of properties of rigid PU foams on dibutyltin dilaurate content.

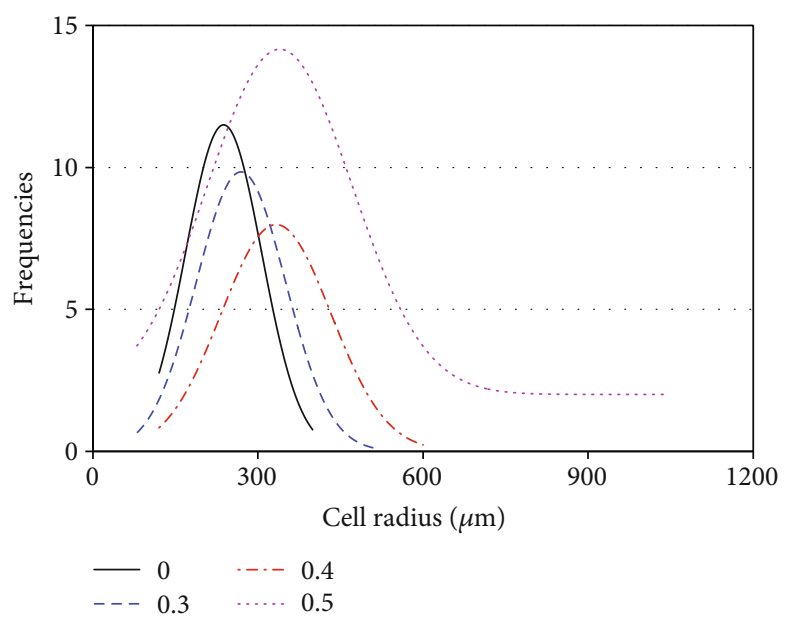

FIgURe 2: Dependence of the pore size distribution on dibutyl dilaurate content.

meaning the denser the polymer network and the greater the foams' compressive strength. However, the larger dibutyltin dilaurate content $(0.5 \mathrm{wt} . \%)$ leads to an increase in the speed of polymerization reaction, resulting in an imbalance between urethane formation reaction and gas release reaction (blowing reaction). This makes the cell size uneven; thereof, the compressive strength reduces. It can be seen from Figure 1 that as the main catalyst content reached $0.3 \mathrm{wt} . \%$, the average pore radius of $\mathrm{Sn} 3$ foam was $13 \%$ higher than that of foam without the main catalyst (Sn0 foam) and 19\% lower than that of $\mathrm{Sn} 4$ foam. As the main catalyst increased to $0.5 \mathrm{wt} . \%$, the average pore radius almost did not grow up, but the standard deviation increased quite sharply. Thus, in general, as the main catalyst content increased, the average pore radius and its standard deviation increased, and the cells became more uneven. It can be observed more clearly in Figure 2. The peaks of the curve became more obtuse and shifted to the right with the increasing main catalyst amount. The end-to-end distance of the curves increased sharply with 


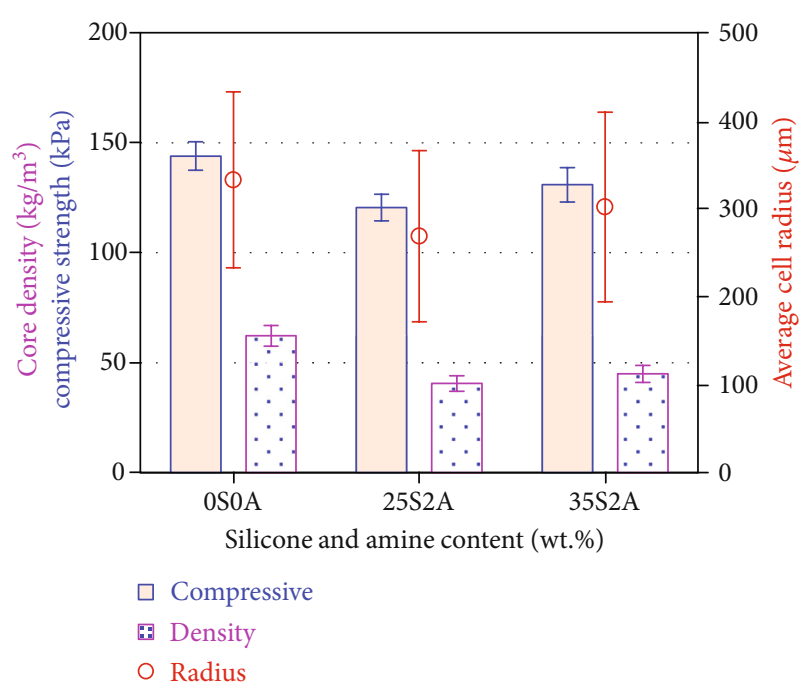

Figure 3: The effect of silicone and amine content on the properties of rigid $\mathrm{PU}$ foam.

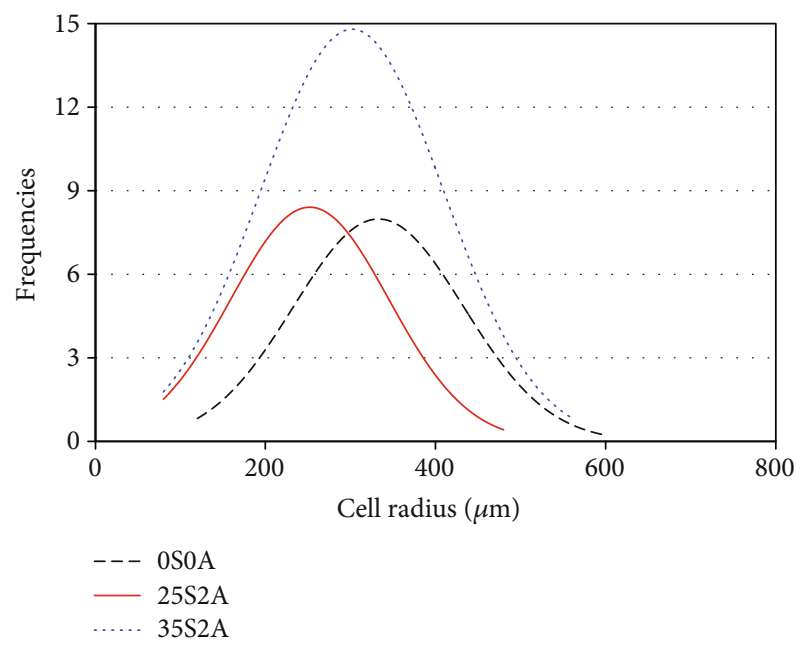

FIgURe 4: Dependence of the pore size distribution on the silicone and amine content.

the main catalyst loading, proving the less uniform size of the cells. It will be necessary to add an agent that helps to make a balance between the polymerization and blowing reactions. On the contrary, as can be seen, the foam's core density is not much affected by the main catalyst content. The foams' core density ranged from 61.82 to $65.02 \mathrm{~kg} / \mathrm{m}^{3}$ (see Figure 1). Based on the results of the compressive strength, core density, average cell radius, and pore uniformity (via standard deviation), $0.4 \mathrm{wt}$.\% is considered to be a suitable dibutyltin dilaurate content.

3.2. Effect of Surfactants. Biopolyol contains not only polar hydroxyl groups but also a lot of nonpolar methylene $\mathrm{CH}_{2}$ groups on the backbone, so the long aliphatic chains of biopolyols are generally hydrophobic, leading to the biopolyol based on rubber seed oil being nonpolar, while the water and glycerol being highly polar. Therefore, in addition to

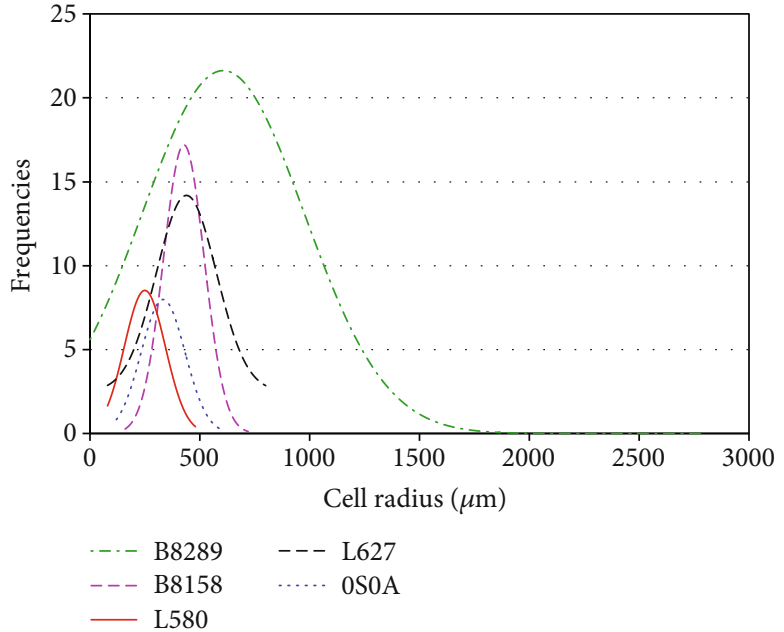

Figure 5: Dependence of the pore size distribution on the surfactants.

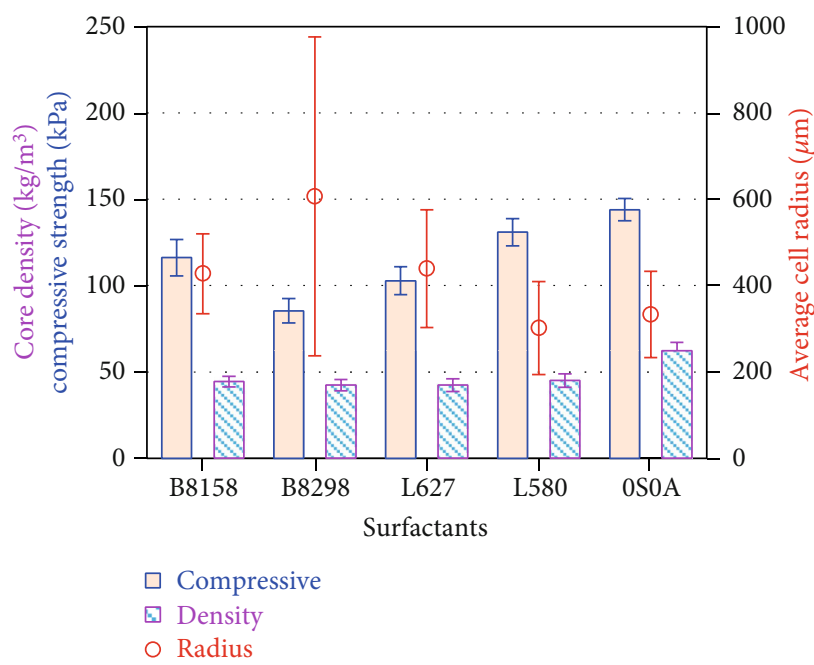

FIgURE 6: The effect of surfactants on the properties of rigid PU foam.

strong agitation, it is necessary to add highly effective surfactants to ensure proper mixing of all ingredients. The surfactant L580 content changed from 0 to $0.35 \mathrm{wt} \%$ as compared to biopolyol with or without the presence of the $0.2 \mathrm{wt} . \%$ cocatalyst (triethylamine). The average pore radius, core density, and compressive strength of 0S0A, 25S2A, and 35S2A foams are shown in Figure 3.

The surface-active materials or surfactants are essential in the manufacture of most polyurethanes because their presence reduces the surface tension, leading to lower core density, thinner cell walls, and less compressive strength of the resulting foams. Figure 3 also shows that the loading of $0.25 \mathrm{wt} . \%$ L580 surfactant and $0.2 \mathrm{wt} . \%$ amines caused a significant decrease in properties of foam such as $35 \%, 19 \%$, and $16 \%$ of the core density, average cell radius, and compressive strength, respectively. By fixing the amine content at $0.2 \mathrm{wt} . \%$ and increasing the silicone content to $0.35 \mathrm{wt} . \%$, 


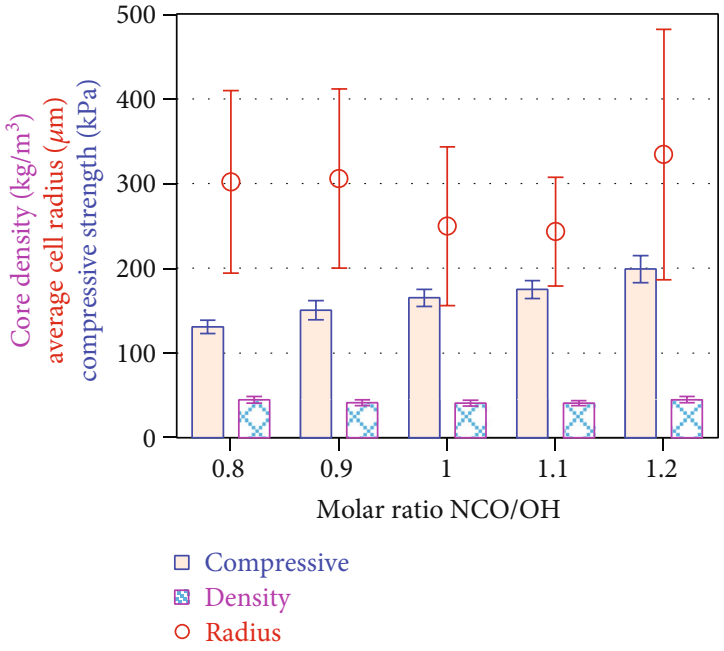

(a)

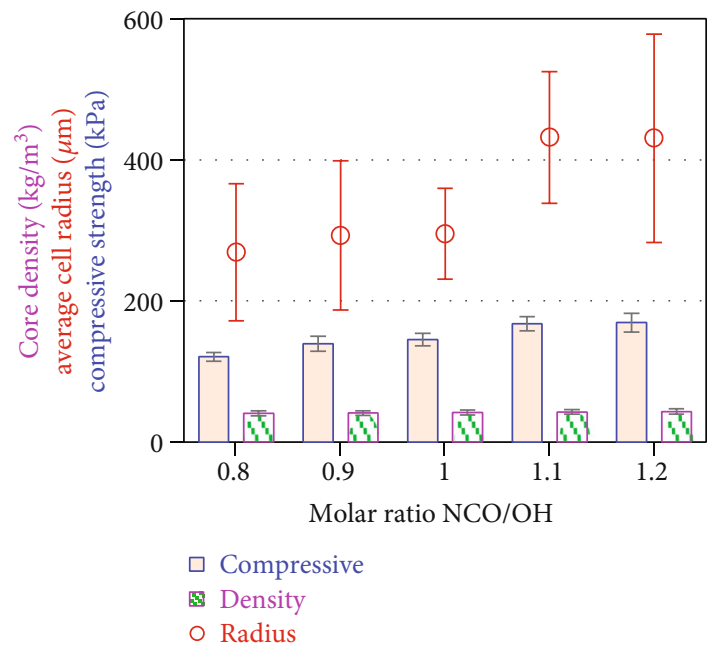

(b)

Figure 7: Dependence of properties of foams (a) 0.35 and (b) 0.25 wt.\% L580 on the NCO/OH ratios.

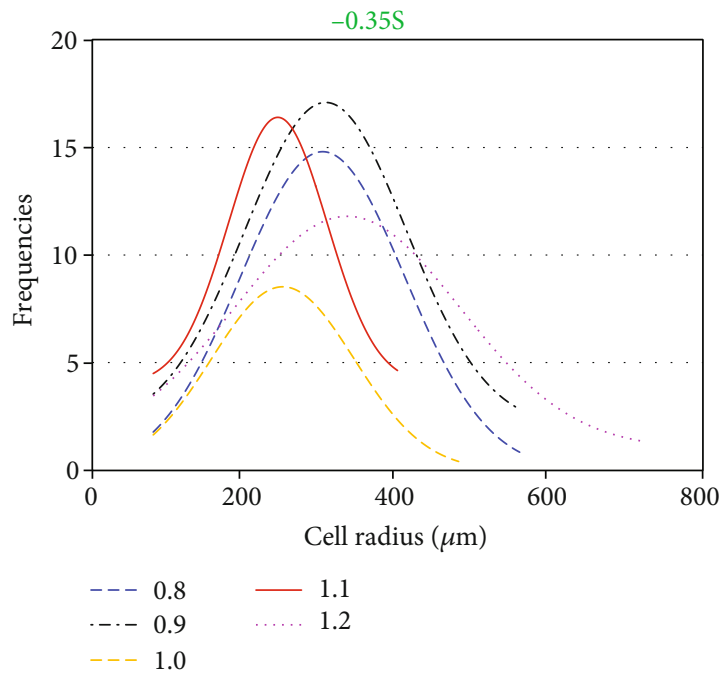

(a)

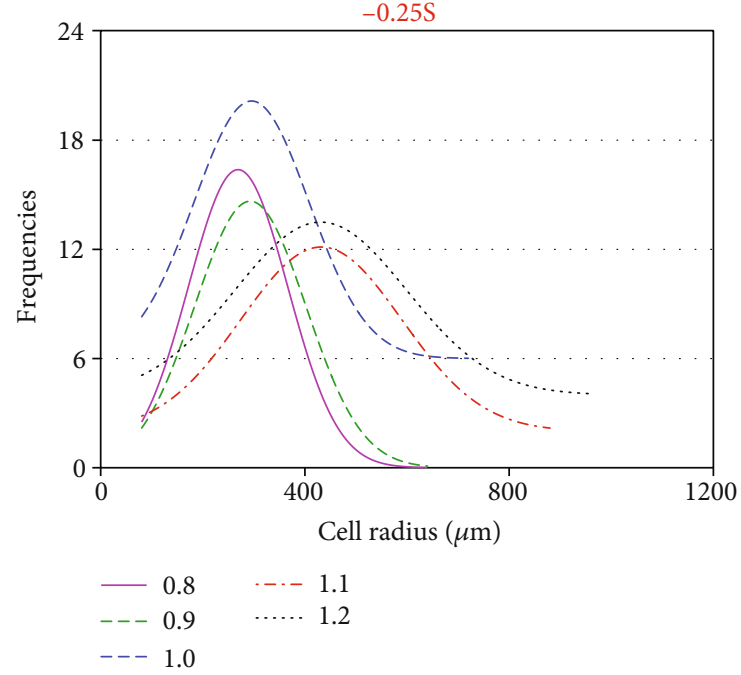

(b)

Figure 8: Dependence of the pore size distribution on the NCO/OH molar ratios.

the average pore radius, core density, and compressive strength of foams increased to $12 \%, 11 \%$, and $8.5 \%$, respectively. In general, the presence of surfactant and amine caused a decrease in compressive strength but had a positive effect on core density and average pore radius (see Figure 3 ). Not only that, the simultaneous presence of amine and surfactant L580 helped to make a balance between the polymerization and blowing reactions, so the pore size was controlled. The curves of frequency tended to move to the left, and the end-to-end distance appeared to be smaller with the presence of surfactant and amine, resulting in more regularity in size and smaller average cell radius (see Figure 4).

With the same amount of amine (0.2 wt.\%) and surfactant ( $0.35 \mathrm{wt} . \%)$, four different types of surfactants were used to prepare foams such as L627, L580, B8158, and B8298. There was a clear difference in the frequency curves corresponding to the four different surfactants as described in
Figure 5. We also see in Figure 5 the curve of L580 foam on the left and the curve of B8298 foam to the right of the other two curves. This means that the average pore radius of L580 foam would be the smallest, while that of B8298 foam-the largest and of the remaining two foams-almost the same. Indeed, such results are clearly seen in Figure 6. Moreover, the end-to-end distances of curves increased to 400,560 , 720 , and $2800 \mu \mathrm{m}$, corresponding to surfactants of L580, B8158, L627, and B8298 (see Figure 5). The cells in the foam using B8298 vary widely in size, but the foams using L580 looked uniform (see Figure 6).

In terms of the average pore radius and cell size uniformity, L580 had a positive effect while the surfactants had a negative effect compared with $0 \mathrm{~S} 0 \mathrm{~A}$ foam without surfactant (see Figures 4 and 5). Due to the lower surface tension, the cell walls become thinner, and the presence of all surfactants reduces the compressive strength of foams. A strong decrease 


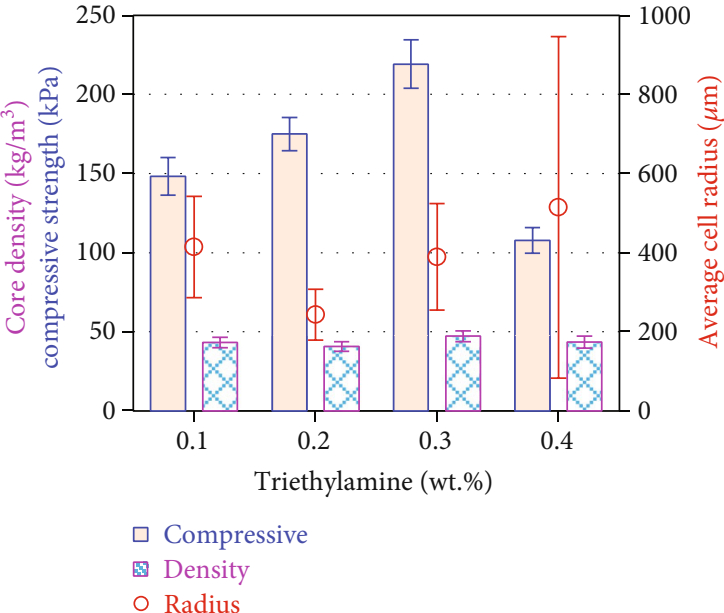

(a)

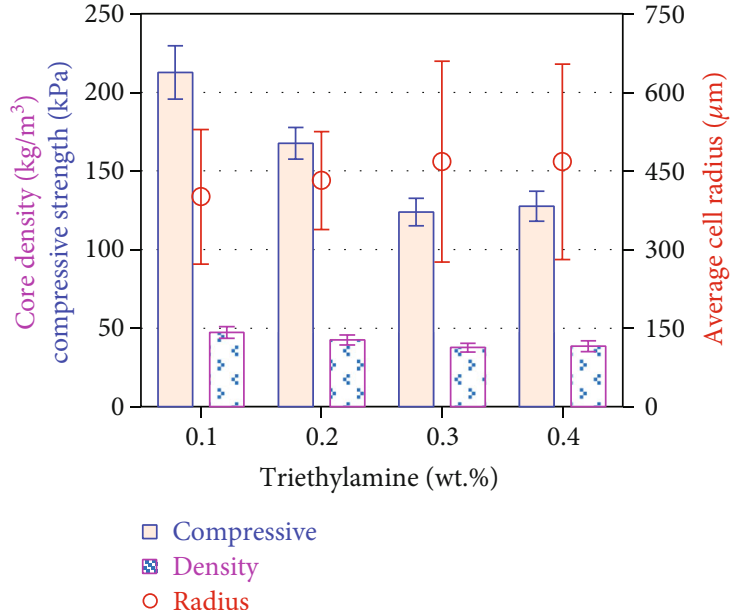

(b)

FIGURE 9: Dependence of the properties of rigid PU foams on the triethylamine content.

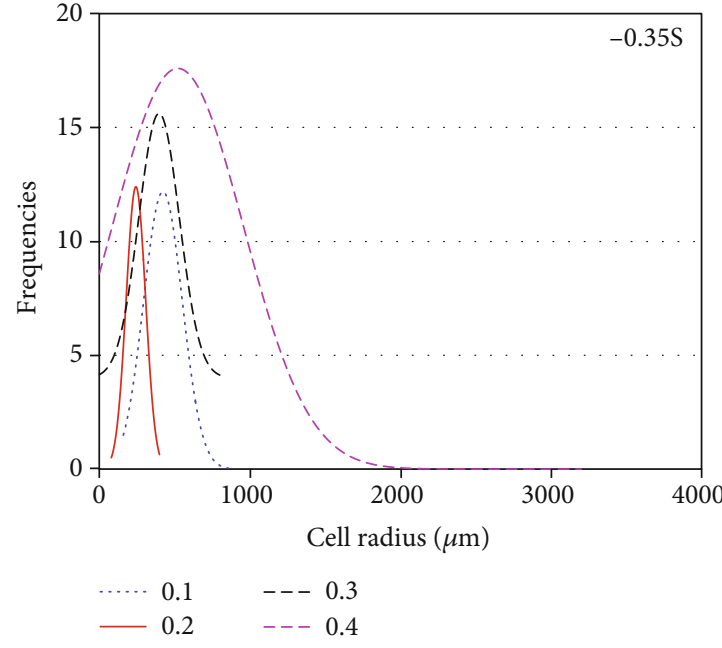

(a)

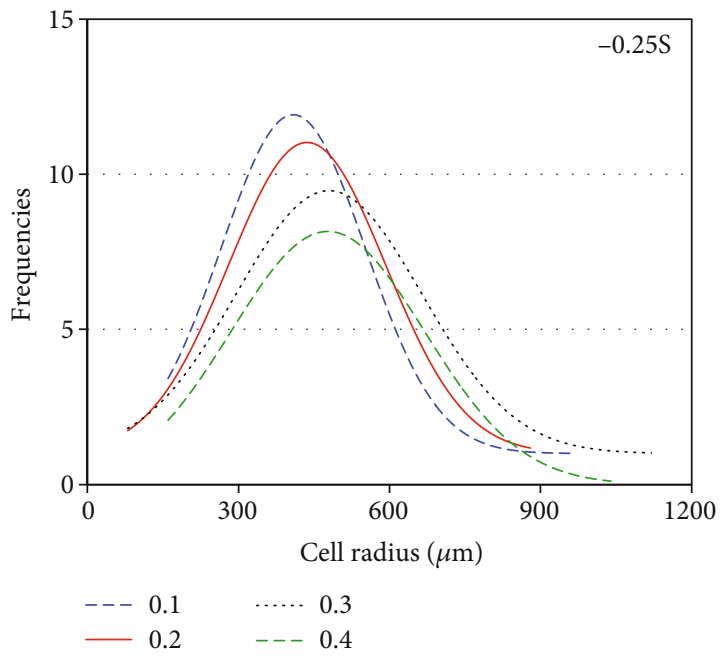

(b)

FIGURE 10: Dependence of the pore size distribution on the triethylamine content.

is seen in the foam sample B8298 by $40 \%$ compared to OSOA foam with no surfactant (see Figure 6). On the contrary, the thinner cell walls have a positive effect on the core density of the foam. As can be seen from Figure 6, the core density of all foams using surfactant was much smaller than that of OSOA foam without surfactant. The core density of foam with surfactant was less influenced by the type of surfactants, and it was $28 \%$ to $30 \%$ lower than that of OSOA foam with no surfactant. From the results of Figures 5 and 6, it is easy to see that out of the four surfactants, L580 was the most suitable for making rigid polyurethane foam using biopolyol.

3.3. Effect of the NCO/OH Molar Ratio. The NCO/OH molar ratio strongly affects the properties of polyurethane foams because it is related to the polymerization reaction. When this ratio grows up, the polyurethane network becomes denser, and the compressive strength will be higher. In this experiment, the $\mathrm{NCO} / \mathrm{OH}$ ratio is variable, from 0.8 to 1.2 . L580 surfactant was used at loading of $0.35 \mathrm{wt} . \%$ for foams 3.1 to 3.5 (see Figure 7(a)) and loading of $0.25 \mathrm{wt} . \%$ for foams 3.6 to 3.10 (see Figure 7(b)) in Table 1. As can be seen from Figure 7 , the compressive strength increased strongly upon the growth of the $\mathrm{NCO} / \mathrm{OH}$ ratio. The compressive strength of the foam using $0.35 \mathrm{wt} . \%$ L580 surfactant was always higher than that of the foam using $0.25 \mathrm{wt} . \%$; meanwhile, the foam using $0.25 \mathrm{wt} . \%$ L580 surfactant has a slightly lower core density at all NCO/OH ratios. Generally, the core density of the foams was low and varied by around $10 \%$.

Not only the polymerization reaction, but the blowing reaction is also governed by the $\mathrm{NCO} / \mathrm{OH}$ ratio. This means the ratio impacts the balance between these two reactions, thus affecting the cell size and uniformity. When using $0.35 \mathrm{wt} . \%$ surfactant, the curve of frequencies tended to shift to the left, and the peak of the curve became sharper as the 
$\mathrm{NCO} / \mathrm{OH}$ ratio enhanced from 0.8 to 1.1 (see Figure $8(\mathrm{a})$ ), meaning that the average pore radius decreased (see Figure $7(\mathrm{a})$ ). On the contrary, in the case of the $\mathrm{NCO} / \mathrm{OH}$ ratio being 1.2, the curve moved to the right, its peak was very obtuse, and hence, this foam had poor uniformity (see Figures $7(\mathrm{a})$ and $8(\mathrm{a}))$. Thus, when using $0.35 \mathrm{wt} . \%$ surfactant, the $\mathrm{NCO} / \mathrm{OH}$ ratio of 1.1 was the most suitable for making rigid polyurethane foam using biopolyol.

When using $0.25 \mathrm{wt}$.\% surfactant, the curves of frequencies tended to shift slightly to the right and the peaks also became more obtuse when the $\mathrm{NCO} / \mathrm{OH}$ ratio increased up to 1 . It is evident that the greater the $\mathrm{NCO} / \mathrm{OH}$ ratio, the clearer the shift to the right of the curve, and the more obtuse the peaks (see Figure 8(b)). These coincided with an increase in the radius and a decrease in the uniformity of the foams, which is most pronounced in foam with the $\mathrm{NCO} / \mathrm{OH}$ ratio of 1.1 and 1.2 (see Figure 7(b)).

3.4. Effect of the Cocatalyst Triethylamine. Amine as a cocatalyst is particularly useful in balancing the rate of two reactions: polymerization and blowing, so amine greatly influences the foams' properties. In each foam recipe, it is essential to find the optimal amine content. As Figure 9(a) shows, when the amine content increased from 0.1 to $0.3 \mathrm{wt} . \%$, the compressive strength of foams using $0.35 \mathrm{wt} . \%$ surfactant increased, whereas it decreased in foams using 0.25 wt.\% surfactant (see Figure 9(b)). If the amine content continued to grow up, the compressive strength of foam using 0.35 wt.\% surfactant reduced remarkably (see Figure 9(a)), but it remained almost unchanged in the case of foam using 0.25 wt. $\%$ surfactant (see Figure 9(b)). The core density of foams using $0.25 \mathrm{wt}$.\% surfactant reduced slightly with the increase in amine content (see Figure 9(b)); meanwhile, in the case of foams using 0.35 wt.\% surfactant, it did not behave so (see Figure 9(a)).

While the compressive strength of A4.25 foam was not much different from that of A3.25 foam (see Figure 9(b)), this value of A4.35 foam was much less than that of A3.35 foam (see Figure 9(a)). This decrease is probably due to the blowing reaction that occurs intensely at large amine content, leading to an imbalance between the blowing and polymerization reactions, resulting in large and unequal cell size. This was clearly shown by the frequency curve of A4.35 foam in Figure 10(a).

In Figure 10(a), we consider two instances of amine content of 0.1 and 0.3 ( $0.35 \mathrm{wt} . \%$ surfactant). Two curves of A1.35 and A3.35 foams were quite similar and were in the same position as the vertical axis. They deviated to the right from the curve of A2.35 foam corresponding to the $0.2 \mathrm{wt} . \%$ amine content. The peaks of all three curves were pointed, especially the peak of A2.35 foam. Thus, the A2.35 foam using $0.2 \mathrm{wt} . \%$ amine content had the smallest average pore size and the largest uniformity (see Figure 9(a)).

Looking at Figure 10(b), when using $0.25 \mathrm{wt} . \%$ surfactant, one can be able to recognize that the curves in this figure shifted to the right, and the peaks became more obtuse upon increasing amine content. Therefore, the average pore radius of cells grew up, and the uniformity of foams was poor, especially foams using 0.3 or 0.4 wt.\% amines (see Figure $9(\mathrm{~b})$ ).
TABLE 2: Raw materials, characteristics, and properties of foams.

\begin{tabular}{|c|c|c|}
\hline & Foam-RSO & Foam-MH \\
\hline Starting materials & \multicolumn{2}{|c|}{ Weight portion } \\
\hline Polyol MH 25646 & 0 & 100 \\
\hline Biopolyol & 100 & 0 \\
\hline Isocyanate Suprasec 5005 & 90 & 105 \\
\hline Water & 4 & 0 \\
\hline Glycerol & 3 & 0 \\
\hline Dibutyltin dilaurate & 0.4 & 0 \\
\hline Triethylamine & 0.2 & 0 \\
\hline Silicone L580 & 0.35 & 0 \\
\hline Characteristics & \multicolumn{2}{|c|}{ Time } \\
\hline Cream time (s) & 45 & 13 \\
\hline Rise time (s) & 180 & 75 \\
\hline Tack-free time (min) & 12 & 10 \\
\hline Properties & \multicolumn{2}{|c|}{ Value } \\
\hline Core density $\left(\mathrm{kg} / \mathrm{m}^{3}\right)$ & $40.73 \pm 3.05$ & $36 \pm 3.03$ \\
\hline Cell radius $(\mu \mathrm{m})$ & $243.2 \pm 64.36$ & $235.68 \pm 63.52$ \\
\hline Compressive strength $(\mathrm{kPa})$ & $175 \pm 10.05$ & $160 \pm 9.85$ \\
\hline Dimensional stability (\%) & $<2$ & $<2$ \\
\hline Water absorption (\%) & 9.13 & 10.23 \\
\hline
\end{tabular}

Thus, the average cell radius of foam using $0.35 \mathrm{wt} . \%$ L580 tended to be smaller than that of foam using 0.25 wt.\% L580. Furthermore, when using 0.35 wt.\% L580 with different cocatalyst content, $0.2 \mathrm{wt} . \%$ triethylamine was the most appropriate.

3.5. Technological Parameters and Properties of Rigid Polyurethane Foams. From the above results, the formulation for rigid biopolyol-based foam (Foam-RSO) has been proposed (see Table 2). Polyol Daltoform MH 25646 is a commercial polyol derived from petroleum. Isocyanate Suprasec 5005 was used to produce rigid foam (Foam-MH). The ingredients such as water, glycerol, tin catalyst, amine catalyst, and silicone surfactant were not included in the Foam-MH recipe because the MH 25646 is an HCFC 141b blown, fully blended polyol.

Because petropolyol contains many primary active hydroxyl groups, it is more reactive in comparison with biopolyol. Thus, biopolyol reacts with isocyanate at a lower rate than petropolyol. It takes a long time for biopolyol to cure in forming rigid foams. Table 2 shows that all the cream time, rise time, and tack-free time of Foam-MH were shorter than those of Foam-RSO.

Foam-MH is based on MH 25646 polyol and contains HCFC $141 \mathrm{~b}$. This is a physical blowing agent, which is significantly less ozone-depleting than chlorofluorocarbons (CFC) but is a substance causing global warming. On the contrary, water is cheap, readily available, and completely environmentally friendly. In this study, water alone was used as a blowing agent for Foam-RSO. The physical blowing agents act by means of evaporation of the liquid, but the chemical agents act by means of chemical reaction forming gases or 


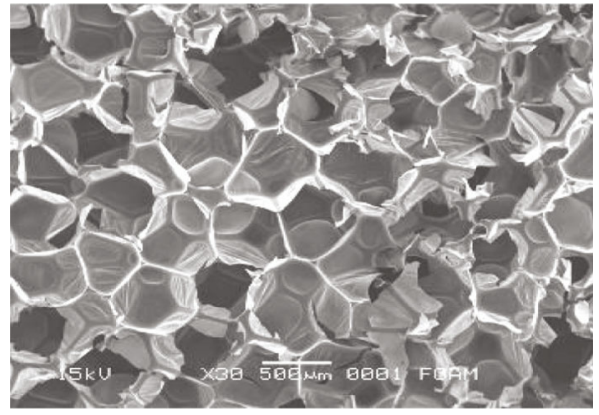

(a)

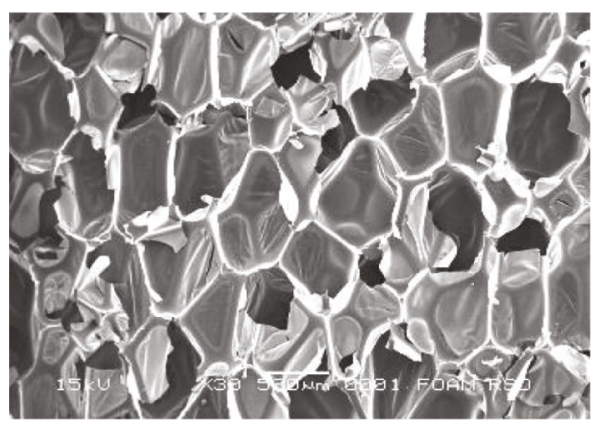

(c)

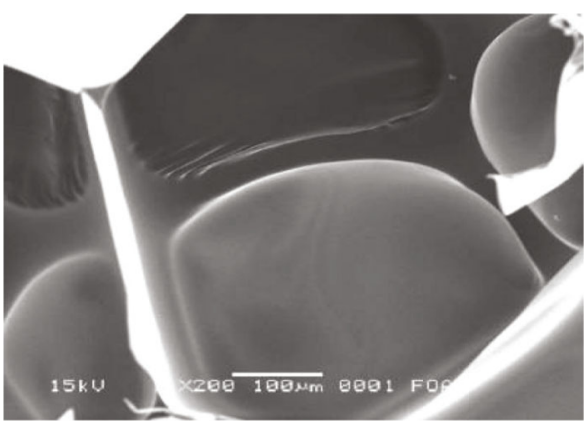

(b)

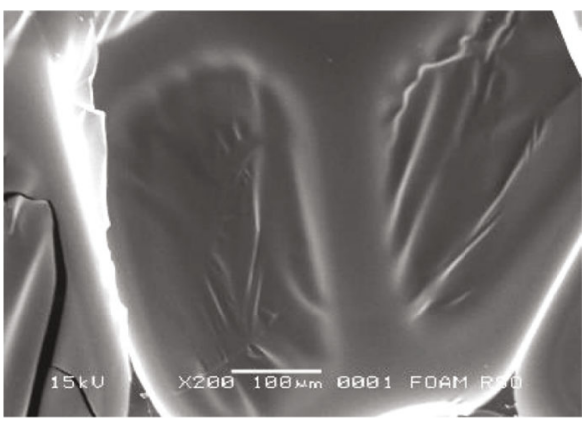

(d)

Figure 11: The SEM images of Foam-MH (a, b) and Foam-RSO (c, d).
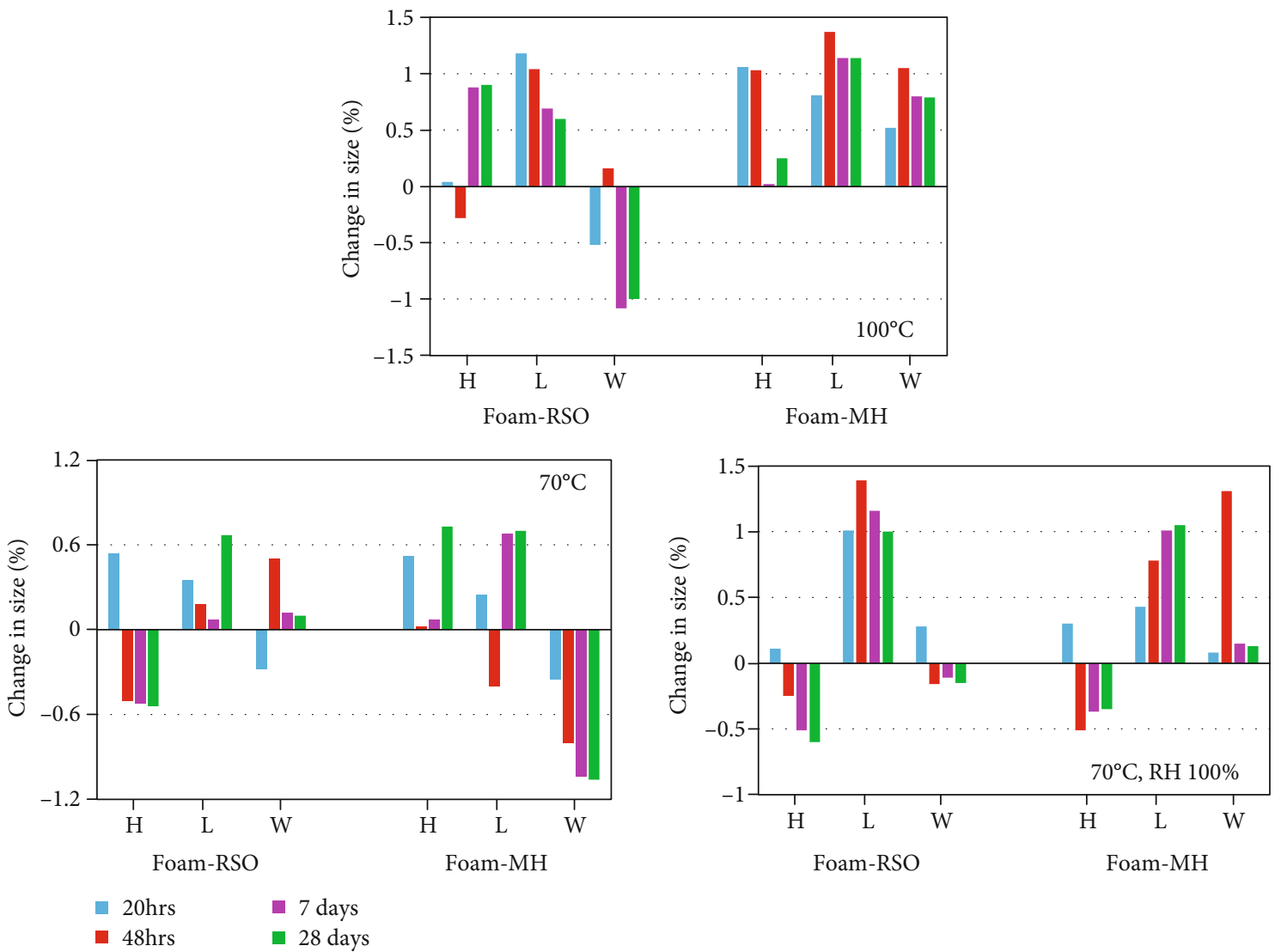

FIGURE 12: The change in the size of foams in environments. H: height; L: length; W: width. 
by-products, so the physical blowing agents usually give a lighter foam. Therefore, Foam-MH would be lighter than Foam-RSO. In other words, the core density of Foam-MH was lower than that of Foam-RSO (see Table 2).

On the other hand, the cell radius of two foams was approximately equal, so the cell walls of Foam-RSO would be thicker than those of Foam-MH, and the compressive strength of Foam-RSO would be slightly higher than that of Foam-MH (see Table 2).

The cellular morphology of rigid foams is presented in Figure 11. Here, it can be seen that the cells of all foams were closed and quite uniform, but the cell size of Foam-MH was slightly smaller than that of Foam-RSO (see Figures 11(a) and $11(\mathrm{c}))$. Therefore, the average cell radius of Foam-MH was $3 \%$ smaller than that of Foam-RSO (see Table 2). On the contrary, the cell walls of the Foam-RSO were a little thicker than those of Foam-MH (see Figures 11(b) and 11(d)). This contributes to the explanation for the $9 \%$ higher compressive strength of Foam-RSO (see Table 2).

On the other hand, the cell radius of two foams was approximately equal, so the cell walls of Foam-RSO would be thicker than those of Foam-MH, and the compressive strength of Foam-RSO would be slightly higher than that of Foam-MH (see Table 2).

3.6. Dimensional Stability of Rigid Foam. The foam samples were prepared according to ISO 2796 standard, and the change in size was measured over time in different environments. Figure 12 shows a change in the size of the foam. When the foams were placed in different environments, the $\mathrm{CO}_{2}$ in the cells of the foams can diffuse out, and at the same time, the air can diffuse into the cells, changing the total inside pressure in the cells, leading to a change in the volume of cells, thus varying the size of the foams. [30]. The results showed that the dimensional stability of both foams after certain time intervals in all environments was less than $2 \%$. Rigid polyurethane foam based on rapeseed polyol [3] has the same dimensional stability as Foam-RSO of this study.

3.7. Water Absorption of Rigid Foams. With both foam types, water absorption increased sharply in the first hours and increased very slowly after about 60 hours of soaking. It is easy to see that in the first 20 hours of immersing, the water absorption of the two foams was almost the same, but the longer the time lasted, the more pronounced the difference in their water absorption (see Figure 13). The cell radius of Foam-MH was slightly smaller than that of Foam-RSO, so the specific surface area of Foam-MH was larger; thus, the Foam-MH would absorb more if it was being soaked in water. After 96 hours of soaking, the water absorption of Foam-RSO was 9.6\%, and that of Foam-MH was $10.23 \%$ (see Table 2).

3.8. Thermal Behavior. As seen in Figure 14, the thermal behavior curves of both Foam-RSO and Foam-MH are quite similar to each other. It has two steps of thermal decomposition. The first degradation step was seen in the range of 150 $\div 450^{\circ} \mathrm{C}$. The second step in the range of $450 \div 800^{\circ} \mathrm{C}$ was due to the chain scission of rubber seed oil and gasification

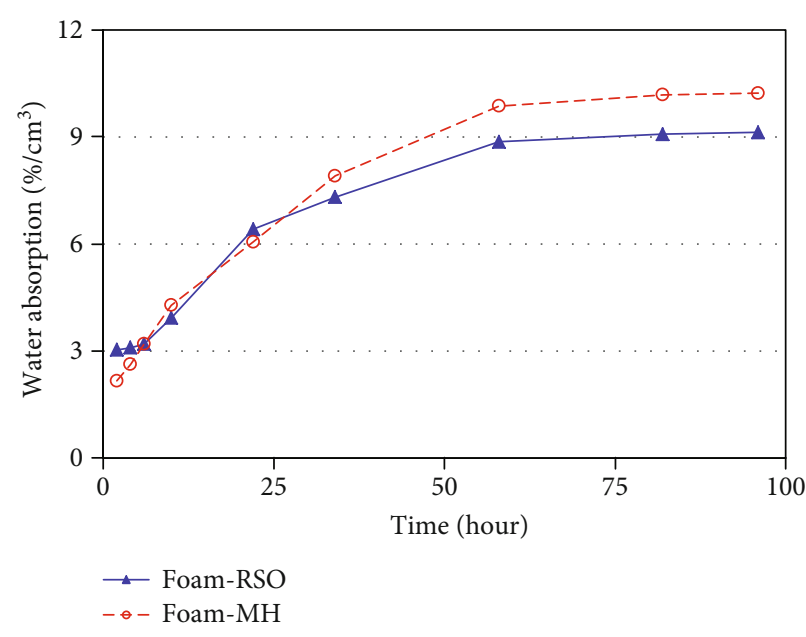

FIGURE 13: The water absorption of Foam-RSO and Foam-MH.

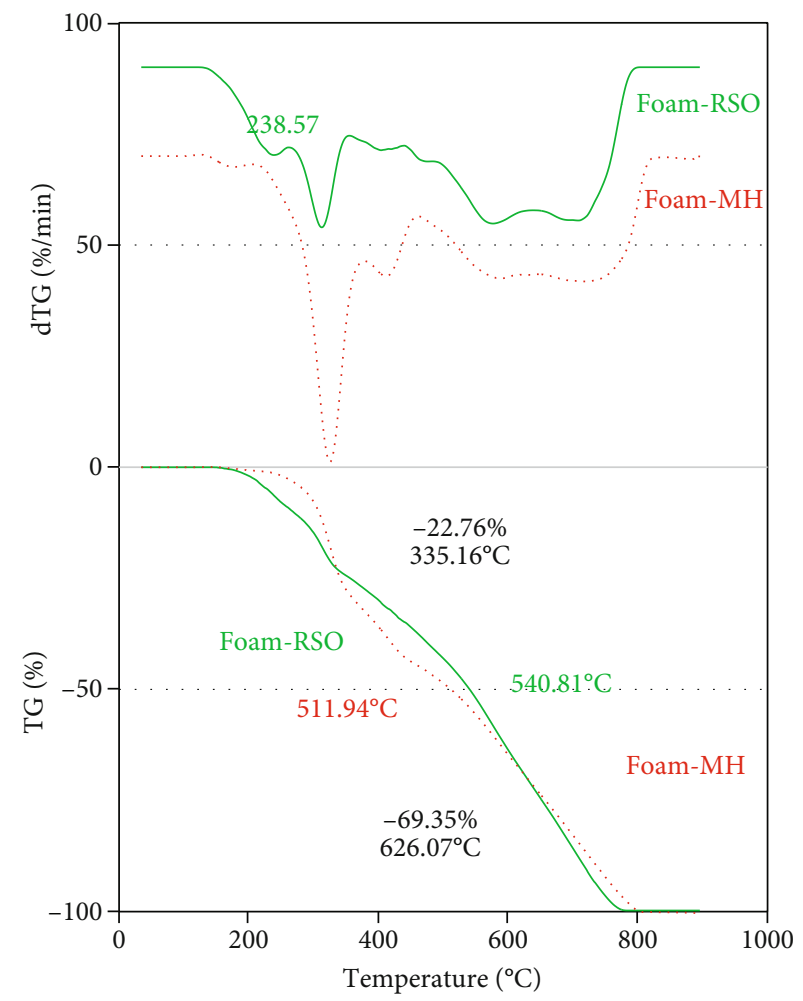

FIgURE 14: Thermooxidative behavior of rigid foam based on polyol of rubber seed oil (Foam-RSO) and petroleum-based polyol (Foam$\mathrm{MH})$ in air.

of any remaining components. The initial decomposition temperature $\left(T_{\text {onset }}\right)$ of Foam-RSO was $174.05^{\circ} \mathrm{C}$ and lower by $2.29^{\circ} \mathrm{C}$ than that of Foam-MH. The weight loss in the first step may be related to the decomposition of linkages in urethane/urea. It includes the dissociation of isocyanate and alcohol, the formation of carbon dioxide from urethane linkages, the formation of olefins and/or primary amines $[1,31$, 32]. There was a difference in the downward peaks of dTG curves. The peak shoulder of the Foam-RSO dTG curve was on the left, and the other was on the right. Therefore, the 
Foam-RSO decomposed faster when the temperature was below $335.16^{\circ} \mathrm{C}$ and decomposition was slower in the range of $335.16 \div 626.07^{\circ} \mathrm{C}$. At temperatures below $335.16^{\circ} \mathrm{C}$, the Foam-RSO foam decomposed somewhat faster, possibly due to the additional breakdown of the ester linkages of glyceride. At higher temperatures, the Foam-RSO decomposed completely faster than others. Moreover, the temperature of $50 \%$ weight loss of Foam-MH was $511.94^{\circ} \mathrm{C}$ and $28.87^{\circ} \mathrm{C}$ lower than that of Foam-RSO.

\section{Conclusions}

In this study, only water was used to serve as a blowing agent. For the formulation of rigid polyurethane, the water content was fixed at 4 wt. $\%$ and the glycerol content at 3 wt. $\%$ compared to the biopolyol. The influence of ingredients in the rigid foam recipe such as the main catalyst (dibutyltin dilaurate), cocatalyst (triethylamine), $\mathrm{NCO} / \mathrm{OH}$ ratio, and surfactant content as well as the type of surfactants on properties of the foams was investigated through the determination of the core density, compressive strength, cell radius, and size distribution. Thereby, a suitable formulation for rigid foams using polyol made from rubber seed oil has been established. The features of the foaming procedure were studied. The mechanical properties, thermal behavior, water absorption, and dimensional stability of foams were all assessed. In comparison with rigid foam based on commercial polyol derived from petroleum, the image of cellular morphology showed that the cells of Foam-RSO also were closed and rather uniform. However, the cell radius of the studied foam was 3\% bigger, and the cell walls were somewhat thicker than those of Foam-MH. It showed that the properties of Foam-RSO were similar to those of Foam-MH. This result would open the possibility of replacing petropolyol with a renewable, inedible oil-based polyol (rubber seed oil-based polyol) in foam fabrication.

\section{Data Availability}

The data used to support the findings of this study are included within the article.

\section{Conflicts of Interest}

The authors declare that there is no conflict of interest regarding the publication of this paper.

\section{Acknowledgments}

This work was supported by Project ĐTĐL.CN-70/19, National Key Laboratory for Polymer \& Composite Materials, Hanoi University of Science and Technology. The authors thank Ms. Nguyen Thi Hong Nga for her assistance.

\section{References}

[1] N. Saetung, S. Somjit, P. Thongkapsri, T. Tulyapitak, and A. Saetung, "Modified rubber seed oil-based polyurethane foams," Journal of Polymer Research, vol. 23, no. 3, pp. 1-10, 2016.
[2] A. Guo, I. Javni, and Z. Petrovic, "Rigid polyurethane foams based on soybean oil," Journal of Applied Polymer Science, vol. 77, no. 2, pp. 467-473, 2000.

[3] Y. H. Hu, Y. Gao, D. N. Wang et al., "Rigid polyurethane foam prepared from a rape seed oil based polyol," Journal of Applied Polymer Science, vol. 84, no. 3, pp. 591-597, 2002.

[4] S. Tan, T. Abraham, D. Ference, and C. W. Macosko, "Rigid polyurethane foams from a soybean oil-based polyol," Polymer, vol. 52, no. 13, pp. 2840-2846, 2011.

[5] S. Das, M. Dave, and G. L. Wilkes, "Characterization of flexible polyurethane foams based on soybean-based polyols," Journal of Applied Polymer Science, vol. 112, no. 1, pp. 299-308, 2009.

[6] S. Miao, S. Zhang, S. Zhiguo, and P. Wang, "Synthesis of biobased polyurethanes from epoxidized soybean oil and isopropanolamine," Journal of Applied Polymer Science, vol. 127, no. 3, pp. 1929-1936, 2013.

[7] I. Javni, Z. S. Petroić, A. Guo, and R. Fuller, "Thermal stability of polyurethanes based on vegetable oils," Journal of Applied Polymer Science, vol. 77, no. 8, pp. 1723-1734, 2000.

[8] L. Zhang, H. K. Jeon, J. Malsam, R. Herrington, and C. W. Macosko, "Substituting soybean oil-based polyol into polyurethane flexible foams," Polymer, vol. 48, no. 22, pp. 6656-6667, 2007.

[9] S. Abdehamid Ahmed, "Effect of polyol/di-isocyanates concentration and temperature on the synthesis of polyurethane foam," International Journal of Engineering Trends and Technology, vol. 17, no. 3, pp. 115-119, 2014.

[10] A. Zlatanić, C. Lava, W. Zhang, and Z. S. Petrović, "Effect of structure on properties of polyols and polyurethanes based on different vegetable oils," Journal of Polymer Science Part B: Polymer Physics, vol. 42, no. 5, pp. 809-819, 2004.

[11] M. Desroches, M. Escouvois, R. Auvergne, S. Caillol, and B. Boutevin, "From vegetable oils to polyurethanes: synthetic routes to polyols and main industrial products," Polymer Reviews, vol. 52, no. 1, pp. 38-79, 2012.

[12] S. Caillol, M. Desroches, G. Boutevin, C. Loubat, R. Auvergne, and B. Boutevin, "Synthesis of new polyester polyols from epoxidized vegetable oils and biobased acids," European Journal of Lipid Science and Technology, vol. 114, no. 12, pp. 14471459, 2012.

[13] N. M. Noor, T. N. M. T. Ismail, Y. S. Kian, and H. A. Hassan, "Synthesis of palm-based polyols: effect of K10 montmorillorite catalyst," Journal of Oil Palm Research, vol. 25, no. 1, pp. 92-99, 2013.

[14] A. A. Beltrán and L. A. Boyacá, "Preparation of oleochemical polyols derived from soybean oil," Latin American Applied Research, vol. 41, no. 1, pp. 69-74, 2011.

[15] C. K. Lyon, V. H. Garrett, and E. N. Frankel, "Rigid urethane foams from hydroxymethylated castor oil, safflower oil, oleic safflower oil, and polyol esters of castor acids," Journal of the American Oil Chemists' Society, vol. 51, no. 8, pp. 331-334, 1974.

[16] A. Campanella, L. M. Bonnaillie, and R. P. Wool, "Polyurethane foams from soyoil-based polyols," Journal of Applied Polymer Science, vol. 112, no. 4, pp. 2567-2578, 2009.

[17] P. Rojek and A. Prociak, "Effect of different rapeseed-oil-based polyols on mechanical properties of flexible polyurethane foams," Journal of Applied Polymer Science, vol. 125, no. 4, pp. 2936-2945, 2012.

[18] S. R. Coles, G. Barker, A. J. Clark et al., "Synthetic mimicking of plant oils and comparison with naturally grown products 
in polyurethane synthesis," Macromolecular Bioscience, vol. 8, pp. 526-532, 2008.

[19] D. Akram, E. Sharmin, and S. Ahmad, "Development and characterization of boron incorporated linseed oil polyurethanes," Journal of Applied Polymer Science, vol. 116, no. 1, pp. 499-508, 2010.

[20] R. de Vasconcelos Vieira Lopes, N. P. D. Loureiro, A. P. T. Pezzin, A. C. M. Gomes, I. S. Resck, and M. J. A. Sales, "Synthesis of polyols and polyurethanes from vegetable oils-kinetic and characterization," Journal of Polymer Research, vol. 20, no. 9, pp. 238-246, 2013.

[21] R. Tanaka, S. Hirose, and H. Hatakeyama, "Preparation and characterization of polyurethane foams using a palm oilbased polyol," Bioresource Technology, vol. 99, no. 9, pp. 3810-3816, 2008.

[22] K. S. Chian and L. H. Gan, "Development of a rigid polyurethane foam from palm oil," Journal of Applied Polymer Science, vol. 68, no. 3, pp. 509-515, 1998.

[23] Y.-C. Chen and W. Tai, "Castor oil-based polyurethane resin for low-density composites with bamboo charcoal," Polymers, vol. 10, no. 10, 2018.

[24] M. A. Mosiewicki, G. A. Dell'arciprete, M. I. Aranguren, and N. E. Marcovich, "Polyurethane foams obtained from castor oil-based polyol and filled with wood flour," Journal of Composite Materials, vol. 43, no. 25, pp. 3057-3072, 2009.

[25] I. O. Bakare, C. Pavithran, F. E. Okieimen, and C. K. S. Pillai, "Synthesis and characterization of rubber-seed-oil-based polyurethanes," Journal of Applied Polymer Science, vol. 109, no. 5, pp. 3292-3301, 2008.

[26] X. Liu, Y. Yang, B. Gao, Y. Li, and Y. Wan, "Environmentally friendly slow-release urea fertilizers based on waste frying oil for sustained nutrient release," ACS Sustainable Chemistry \& Engineering, vol. 5, pp. 6036-6045, 2017.

[27] R. Noyori, M. Aoki, and K. Sato, "Green oxidation with aqueous hydrogen peroxide," Chemical Communications, vol. 34, no. 16, pp. 1977-1986, 2003.

[28] P. Jiang, M. Chen, Y. Dong, Y. Lu, X. Ye, and W. Zhang, "Novel two-phase catalysis with organometallic compounds for epoxidation of vegetable oils by hydrogen peroxide," Journal of the American Oil Chemists' Society, vol. 87, no. 1, pp. 8391, 2010.

[29] N. T. Thuy, T. Q. Vuong, and V. M. Duc, "Effects of glycerol and $\mathrm{NCO} / \mathrm{OH}$ on rigid polyurethane foam based on biopolyol of rubber seed oil using water as blowing agent," Vietnam Journal of Chemistry, vol. 58, no. 3, pp. 392-397, 2020.

[30] C. Cecchini, R. Zannetti, and A. Stefani, "Dimensional stability of polyurethane rigid foams blown with $\mathrm{CO}_{2}$," Journal of Cellular Plastics, vol. 35, pp. 514-530, 2015.

[31] Z. S. Petrović, L. Yang, A. Zlatanić, W. Zhang, and I. Javni, "Network structure and properties of polyurethanes from soybean oil," Journal of Applied Polymer Science, vol. 105, no. 5, pp. 2717-2727, 2007.

[32] Y. Lu and R. C. Larock, "Soybean-oil-based waterborne polyurethane dispersions: effects of polyol functionality and hard segment content on properties," Biomacromolecules, vol. 9, no. 11, pp. 3332-3340, 2008. 